\title{
Trial Evaluation of Visceral Fat Characteristics by Abdominal Bioelectrical Impedance Method
}

\author{
Yutaka Yamanaka*, Hiromi Shinno, Satoshi Kurose, Hiromi Tsutsumi and Yutaka Kimura
}

Department of Health Science, Graduate School of Medicine, Kansai Medical University, Japan

\begin{abstract}
Aim: As the abdominal bioelectrical impedance method is changed by visceral fat area by CT (VFA) and quantity, we examined whether the abdominal bioelectrical impedance per measured area (V/A) as the visceral fat characteristics index is useful for diabetes care.

Methods: The subjects were 33 Japanese obese female outpatients. We investigated the correlations of V/A measured by the abdominal bioelectrical impedance method device and of VFA, for each measurement item. And we analyzed the related factors for HOMA-R as the insulin resistance index and for V/A as visceral fat characteristics index by stepwise multiple regression analysis.

Results: As there is no correlation between the V/A we used and VFA, we report that the visceral fat characteristics (density) from VIA is not directly associated with VFA (area). We investigated correlations of VIA and VFA for the measured items. There were significant correlations of VIA for peakVO /W, BS, IRI, HOMA-R, lean body. There were significant correlations of VFA for peakVO $/ \mathrm{W}$, IRI and HOMA-R, BMI, waist circumference, and body weight. We analyzed the related factors for HOMA-R and for VIA by stepwise multiple regression analysis. From the results of stepwise multiple regression analysis, the final independent variables VIA and VFA were chosen for HOMA-R, and peakVO $/ 2 \mathrm{~W}$ was chosen for V/A.

Conclusion: We report that the visceral fat characteristics (density) from V/A are not directly associated with VFA (area). Hence the evaluation of visceral fat characteristics by VIA is important for diabetes care and treatment of obesity.
\end{abstract}

Keywords: Visceral fat characteristics; Bioelectrical impedance; Insulin resistance; HOMA-R; Visceral fat area

Abbreviations: VFA: Visceral Fat Area; WC: Waist Circumference; CT: Computed Tomography; V: Abdominal Visceral Fat Impedance; V/A: Abdominal Visceral Fat Impedance per Area

\section{Introduction}

It has been shown that abdominal visceral fat is associated with the onset mechanism for the metabolic syndrome caused by obesity, which induces prospective arteriosclerotic diseases such as diabetes, mellitus, hyperlipidemia and hypertension [1-4]. Abdominal visceral fat area (VFA) is reported to be negatively correlative with plasma adiponectin as adipocytokine for ordinary persons, and to increase the risk of arteriosclerotic and diabetes disease [5,6]. In the past, visceral fat has been evaluated only by area. However, visceral fat varies in weight and specific gravity. The difference in fat-specific gravity is associated with various physiologically activated functions, which adipose tissue induces. It is reported that visceral fat in particular induces adipocytokine more than does subcutaneous fat; visceral fat is therefore associated with insulin resistance and other conditions $[3,7]$. As visceral fat increases, internal secretion metabolism relationship disease is reported to increase disease incidence and severity of excess stored subcutaneous fat $[2,4,8]$. We therefore believe that the evaluation of visceral fat not only by area but also by quantitative characteristics analysis is very important in evaluating arteriosclerotic disease risk and diabetes care.

Bioelectrical impedance method can estimate constituent tissue and quantity of organism by bioelectrical impedance, which is measured by passing a low-level electrical current through the body $[9,10]$. Recently, the bioelectrical impedance method has been used in the abdominal area. Ryo measured abdominal visceral fat impedance and waist circumference (WC) and estimated abdominal VFA, which is called eVFA method. Ryo's studies indicate that eVFA method is highly correlative with VFA measured by computed tomography (CT) [11] It was reported that estimated VFA by eVFA method is significantly associated with arteriosclerotic risk [12].

The eVFA method can be changed by VFA and quantity, which is associated with visceral fat tissue characteristics. Therefore, we divided the measured abdominal visceral fat impedance $(\mathrm{V})$ by the measuring area, which means abdominal visceral fat impedance per area (V/A). The V/A can be expressed as the index of visceral fat characteristics and/or quantity. If we can evaluate $\mathrm{V} / \mathrm{A}$ in relation to visceral fat characteristics, we can evaluate visceral fat function which corresponds to visceral fat characteristics.

In this study, we calculated V/A from the measured $\mathrm{V}$ using the eVFA method and investigated the correlation of VFA and of V/A in terms of motor abilities and humoral arteriosclerotic risk factors for the obese patients. Our purpose was to determine the usefulness of V/A analysis relative to the index of visceral fat characteristics.

${ }^{*}$ Corresponding author: Yutaka Yamanaka, Department of Health Science, Graduate School of Medicine, Kansai Medical University, 2-5-1, Shinmachi, Hirakata, Osaka 5731010, Japan, Tel: +81-72-804-2334, E-mail: yamanaka.yutaka@jp.panasonic.com

Received July 24, 2013; Accepted September 17, 2013; Published October 28 2013

Citation: Yamanaka Y, Shinno H, Kurose S, Tsutsumi H, Kimura Y (2013) Trial Evaluation of Visceral Fat Characteristics by Abdominal Bioelectrical Impedance Method. J Diabetes Metab 4: 292. doi:10.4172/2155-6156.1000292

Copyright: (c) 2013 Yamanaka Y, et al. This is an open-access article distributed under the terms of the Creative Commons Attribution License, which permits unrestricted use, distribution, and reproduction in any medium, provided the original author and source are credited. 
Citation: Yamanaka Y, Shinno H, Kurose S, Tsutsumi H, Kimura Y (2013) Trial Evaluation of Visceral Fat Characteristics by Abdominal Bioelectrical Impedance Method. J Diabetes Metab 4: 292. doi:10.4172/2155-6156.1000292

\section{Methods}

The study subjects were obese female outpatients $(n=33)$ at our university hospital in Osaka. They were obese women (age: 20- years old, BMI: 30-) without serious medical conditions. The exclusion criteria were diabetes insulin treatment, secondary obesity by endocrine disorders and mental illness drug treatment. The study period was from 15 February, 2011 to 31 October, 2012. The study was approved by the Human Ethics Committee of our university.

First, we identified V/A. The voltage, occurring at the flank by the flow of current between the umbilicus and the back, correlates significantly with VFA and is unaffected by subcutaneous fat area. The voltage becomes higher as visceral fat accumulates even in subjects with the same WC because the electrical resistance of intra-abdominal fat is greater than that of fat-free mass, and the density of the equipotential lines between the two ventral electrodes is greater [11] (Figure 1). In this study, we developed a measuring device based on Ryo's et al. [11]

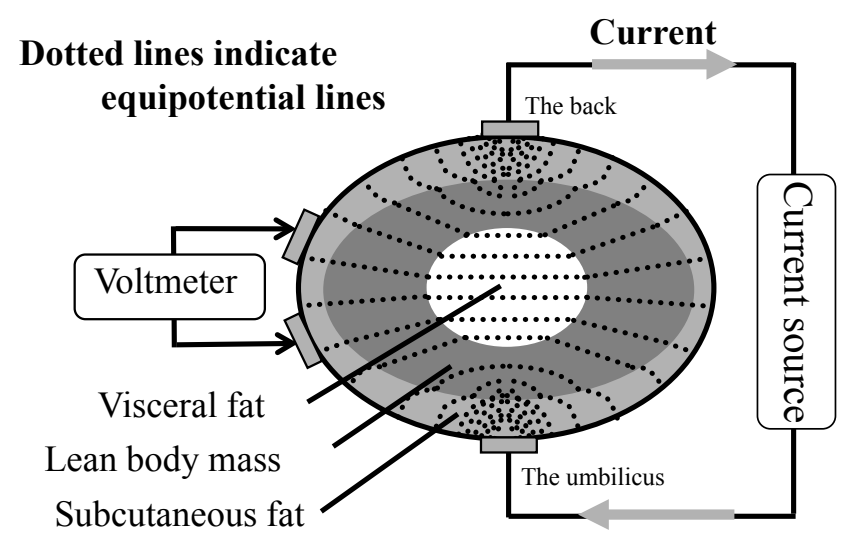

Figure 1: Abdominal bioelectrical impedance method

(1) The voltage occurring at the flank to the flow of current between the umbilicus and the back correlates significantly with VFA

(2) The voltage occurring is unaffected by subcutaneous fat, because it is located in abdominal cavity.

(3) The voltage becomes higher as visceral fat accumulates even in subjects with the same WC because the electrical resistance of intra-abdominal fat is greater than that of fat-free mass, and the density of the equipotential lines between the two ventral electrodes becomes greater.

(This figure is based on Ryo's developed eVFA method [11])

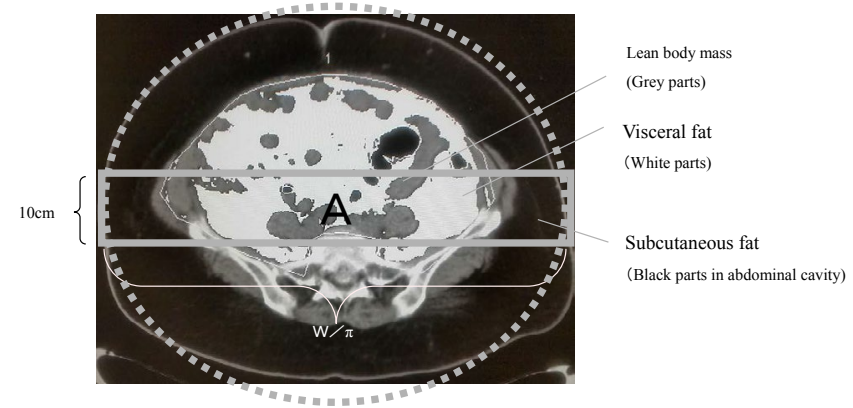

Figure 2: The definition of VIA by eVFA method

(1) The measured area is $A$

(2) The distance between the two ventral part electrodes is $10 \mathrm{~cm}$

(3) Assuming abdomen is circle, the radius is $W / 2 \pi$. Therefore $A$ is calculated as $A=10^{*}(W / \pi)$.

(4) We calculated B (visceral fat area ratio in A from CT). We compensated for the approximate value of visceral fat area in the measured area by multiplying. This can be expressed as:

$\mathrm{V} / \mathrm{A}=\mathrm{V} /\left(\mathrm{B}^{*} 10^{*} \mathrm{WC} / 3.14\right)$, where $\pi$ is 3.14 principle, which sets the distance of the two ventral electrodes to $10 \mathrm{~cm}$, current $\mathrm{Hz}$ to $100 \mathrm{kHz}$, and current to $1 \mathrm{~mA}$. We measured the voltage between the two ventral electrodes, and integrated it each $200 \mathrm{msec}$. We measured the subjects in the same bodily region more than two hours after eating on three occasions. We calculated the average as V. Our V/A definitions are below.

1. The measured area is A (Figure 2)

2. The distance between the two ventral electrodes is $10 \mathrm{~cm}$.

3. Assuming the abdomen is a circle, the radius is $\mathrm{WC} /(2 \pi)$. Therefore, $\mathrm{A}$ is calculated as $\mathrm{A}=10^{*} \mathrm{WC} / \pi$ ).

4. The measured area $\mathrm{A}$ includes both visceral and subcutaneous fat. We calculated B, which is the ratio of visceral fat area in A using CT (Light Speed VCT VISION: GE Healthcare Japan Co., Ltd., Japan) photographic data for all subjects. We compensated for the approximate value of visceral fat area in the measured area by multiplying A by B.

As a result, V/A can be expressed as

$\mathrm{V} / \mathrm{A}=\mathrm{V} /\left(\mathrm{B}^{\star} 10^{*} \mathrm{WC} / 3.14\right)$, where $\pi \mathrm{is} 3.14, \mathrm{~V}(\mathrm{~m} \Omega), \mathrm{WC}(\mathrm{cm})$

Second, we investigated the correlations of V/A measured by eVFA method device (Panasonic Co., Ltd. trial device, Japan) and of VFA by CT, for each measurement item. We measured abdominal CT, motor abilities, fasting humoral factors, baPWV and blood pressure on the same day that we measured V or within one week before or after. The fasting humoral factors we measured were blood sugar level (BS), immunoreactive insulin (IRI), HOMA-R, adiponectin, high molecular weight adiponectin, middle molecular weight adiponectin, low molecular weight adiponectin, triglyceride (TG), low-density lipoprotein cholesterol (LDL-C), high-density lipoprotein cholesterol (HDL-C), uric acid (UA), Hemoglobin A1c (HbA1c: National Glycohemoglobin Standardization Program value), and C-reactive protein (CRP). We obtained average brachial-ankle pulse wave velocity (baPWV) at the right and left ankles, systolic blood pressure (SBP), and diastolic blood pressure (DBP) by BP-203RPE III (Omron-Colin Co., Ltd., Japan) as the arteriosclerosis quantitative index. We calculated visceral fat area and subcutaneous fat area by CT as the abdominal fat index, and measured WC, body weight, and body mass index (BMI), and obtained fat body mass and lean body mass by DEXA (Dual Energy X-ray Absorptiometry: DPX-NT: General Electric Lunar Co., Ltd., America). To determine the motor abilities index we measured anaerobic threshold $\mathrm{VO}_{2}$ per body weight $\left(\mathrm{ATVO}_{2} / \mathrm{W}\right)$ and peak $\mathrm{VO}_{2}$ per body weight (peakVO $/ \mathrm{W}$ ) for cardiopulmonary exercise test by sedentary ergometer using AE1000 (Minato Co., Ltd., Japan).

Finally, we analyzed the related factors for HOMA-R as the insulin resistance index and for V/A as visceral fat characteristics indexes by stepwise multiple regression analysis.

All statistical analysis was performed with SPSS Statistics 19.0. Pearson's correlation coefficient was used to analyze the correlations. Significance level was set at $\mathrm{P}<0.05$ (two-sided test).

\section{Results}

\section{Identification of the calculation formula for V/A}

We calculated B, which is the ratio of visceral fat area in A from photographic data for 33 subjects (age $44.8 \pm 12.2$ years old, BMI 36.1 \pm 4.4 , WC $115.8 \pm 9.4 \mathrm{~cm}$ : Average $\pm \mathrm{SD})$. Average $\mathrm{B}$ was $36 \pm 6 \%(\max$ $48 \%$, min $20 \%$ ). Hence we identified $\mathrm{B}=0.36$. As a result, we used the calculation formula for $\mathrm{V} / \mathrm{A}\left(\mathrm{V} / \mathrm{A}=\mathrm{V} /\left(0.36^{\star} 10^{\star} \mathrm{WC} / 3.14\right)\right)$ in this study. 


\section{The correlations of V/A for measured items}

i. Basic data for all subjects are shown in Table 1. To confirm whether V/A is an independent index of visceral fat characteristics, we investigated correlations of V/A for visceral fat area and subcutaneous fat area by CT, WC, and body weight. There were no significant correlations of V/A for their indexes.

ii. We show the correlations of V/A and VFA by CT for measured items (Table 2). As for $\mathrm{V} / \mathrm{A}$, there was a significant negative correlation for peakVO$_{2} / \mathrm{W}$ in motor abilities; significant positive correlations for BS, IRI and HOMA-R in fasting humoral factors; and significant negative correlation for lean body mass. As for VFA by CT, there was a significant negative correlation for peakVO $/ \mathrm{W}$ in motor abilities; significant positive correlations for IRI and HOMA-R in fasting humoral

\begin{tabular}{|c|c|c|}
\hline & Average & SD \\
\hline Age (year) & 44.8 & 12.2 \\
\hline Body weight (kg) & 89.4 & 10.1 \\
\hline Body mass index $\left(\mathrm{kg} / \mathrm{m}^{2}\right)$ & 36.0 & 4.4 \\
\hline Waist circumference $(\mathrm{cm})$ & 115.8 & 9.4 \\
\hline Visceral fat area $\left(\mathrm{cm}^{2}\right)$ & 176.6 & 55.8 \\
\hline Subcutaneous fat area $\left(\mathrm{cm}^{2}\right)$ & 456.6 & 103.5 \\
\hline Fat body mass $(\mathrm{kg})$ & 49.1 & 12.3 \\
\hline Lean body mass $(\mathrm{kg})$ & 43.8 & 4.9 \\
\hline ATVO $_{2}(\mathrm{ml} / \mathrm{kg} / \mathrm{min})$ & 11.4 & 2.3 \\
\hline peakVO $(\mathrm{ml} / \mathrm{kg} / \mathrm{min})$ & 19.0 & 4.0 \\
\hline baPWV:Right and left average $(\mathrm{cm} / \mathrm{sec})$ & 1343.2 & 250.9 \\
\hline $\mathrm{SBP}(\mathrm{mmHg})$ & 143.3 & 17.0 \\
\hline $\mathrm{DBP}(\mathrm{mmHg})$ & 86.0 & 12.5 \\
\hline Adiponectin (ng/mL) & 4.9 & 3.0 \\
\hline High molecular weight adiponectin ( $\mathrm{ng} / \mathrm{mL})$ & 1.9 & 2.0 \\
\hline Middle molecular weight adiponectin $(\mathrm{ng} / \mathrm{mL})$ & 0.9 & 0.5 \\
\hline Low molecular weight adiponectin $(\mathrm{ng} / \mathrm{mL})$ & 2.0 & 0.9 \\
\hline $\mathrm{BS}(\mathrm{mg} / \mathrm{dl})$ & 101.4 & 17.0 \\
\hline $\mathrm{IRI}(\mu \mathrm{u} / \mathrm{ml})$ & 12.2 & 5.3 \\
\hline HOMA-R & 3.1 & 1.6 \\
\hline TG (mg/dl) & 112.8 & 44.1 \\
\hline HDL-C (mg/dl) & 48.4 & 9.5 \\
\hline LDL-C (mg/dl) & 119.1 & 30.7 \\
\hline $\mathrm{UA}(\mathrm{mg} / \mathrm{dl})$ & 5.9 & 1.3 \\
\hline $\mathrm{HbA1c}(\%)$ & 6.0 & 1.0 \\
\hline CRP (mg/dl) & 0.5 & 0.6 \\
\hline $\mathrm{V} / \mathrm{A}\left(\mathrm{m} \Omega / \mathrm{cm}^{2}\right)$ & 10.9 & 2.6 \\
\hline
\end{tabular}

Table 1: Basic data for all subjects $(n=33)$.

\begin{tabular}{|l|c|c|c|c|}
\hline \multirow{2}{*}{} & \multicolumn{3}{|c|}{ Correlations for V/A $\left(\mathrm{m} \Omega / \mathrm{cm}^{2}\right)$} & \multicolumn{2}{|c|}{$\begin{array}{c}\text { Correlations for VFA } \\
\left(\mathrm{cm}^{2}\right) \text { by CT }\end{array}$} \\
\cline { 2 - 5 } & $\mathrm{r}$ & $\mathrm{p}$ value & $\mathrm{r}$ & $\mathrm{p}$ value \\
\hline Body weight & -0.20 & n.s. & 0.35 & $\mathrm{p}<0.05$ \\
\hline BMI & -0.11 & n.s. & 0.43 & $\mathrm{p}<0.05$ \\
\hline Waist circumference & -0.23 & n.s. & 0.44 & $\mathrm{p}<0.01$ \\
\hline Lean body mass & -0.64 & $\mathrm{p}<0.01$ & 0.09 & $\mathrm{n} . \mathrm{s}$. \\
\hline peakVO 2 (ml/kg/min) & -0.49 & $\mathrm{p}<0.05$ & -0.49 & $\mathrm{p}<0.05$ \\
\hline BS & 0.52 & $\mathrm{p}<0.01$ & 0.20 & $\mathrm{n} . \mathrm{s}$. \\
\hline IRI & 0.48 & $\mathrm{p}<0.01$ & 0.43 & $\mathrm{p}<0.05$ \\
\hline HOMA-R & 0.60 & $\mathrm{p}<0.01$ & 0.41 & $\mathrm{p}<0.05$ \\
\hline
\end{tabular}

We indicate the only significant correlations of VIA or VFA by CT. n.s.: no significance

Table 2: Correlations of VIA and VFA by CT for measured items $(n=33)$

\begin{tabular}{|l|c|c|}
\hline \multirow{2}{*}{} & \multicolumn{2}{|c|}{ Correlations of HOMA-R } \\
\cline { 2 - 3 } VIA & $r$ & $p$ value \\
\hline VFA by CT & 0.60 & $p<0.01$ \\
\hline baPWV:Right and left average & 0.41 & $p<0.05$ \\
\hline BS & 0.40 & $p<0.05$ \\
\hline IRI & 0.63 & $p<0.01$ \\
\hline HbA1c & 0.92 & $p<0.01$ \\
\hline
\end{tabular}

We indicate the only significant correlations of HOMA-R

Table 3: Correlations of HOMA-R for measured items $(n=33)$.

factors; and significant positive correlations for BMI, WC, and body weight.

\section{Stepwise multiple regression analysis results for HOMA-R and $\mathrm{V} / \mathrm{A}$}

There were significant correlations of HOMA-R for V/A, VFA by CT, baPWV, BS, and IRI (Table 3). As HOMA-R is calculated from BS and IRI, we excluded BS and IRI from stepwise multiple regression analysis items. The results of stepwise multiple regression analysis (dependent variable: HOMA-R; independent variables: V/A, VFA by CT, baPWV) indicated that final significant independent variables were V/A (standardization coefficient; 0.54, $<<0.001$ ) and VFA by CT (standardization coefficient; $0.30, \mathrm{p}<0.05$ ). Adjusted $\mathrm{R}^{2}$ is 0.41 . There were significant correlations of $\mathrm{V} / \mathrm{A}$ for $\mathrm{peakVO}_{2} / \mathrm{W}, \mathrm{BS}$, IRI and HOMA-R, lean body mass (Table 2). To confirm what is the most significant correlation of V/A except HOMA-R, BS, and IRI, we performed stepwise multiple regression analysis (dependent variable: V/A; independent variables: peakVO $/ \mathrm{W}$, lean body mass). As a result, we confirmed that the final significant independent variable was peakVO $2 / \mathrm{W}$ (standardization coefficient; $-0.49, \mathrm{p}<0.05$ ). Adjusted $\mathrm{R}^{2}$ is 0.21

\section{Disscusion}

The results suggest that the measured abdominal bioelectrical impedance (V), in which the voltage occurs at the flank by the flow of current between the umbilicus and the back, correlates significantly with VFA according to Ryo's developed eVFA method [11] and V significantly indicates visceral fat characteristics. Hence we estimate visceral fat characteristics from $\mathrm{V}$ in this study. As there is no correlation between the V/A we used and VFA measured by CT, we report that the visceral fat characteristics (density) from V/A is not directly associated with VFA by CT (area). These results indicate that the evaluation of visceral fat characteristics from V/A is important in relationship to insulin resistance and other factors, which significantly correlate with the visceral fat. As there are no significant correlations of V/A for the visceral fat area and subcutaneous fat area by CT, WC, and body weight, $\mathrm{V} / \mathrm{A}$ is shown to be a new independent index. Typically, high density in adipose tissue indicates high bioelectrical impedance $[9,10]$. Therefore, high density in visceral adipose tissue indicates high V/A, and low density in visceral adipose tissue indicates low V/A.

For the 33 obese female outpatients, there were significant positive correlations of both V/A and VFA by CT with HOMA-R. However, we chose both the V/A and the VFA measured by CT as final significant independent variables based on the results of stepwise multiple regression analysis. We therefore suggest that HOMA-R is associated not only with VFA but also with visceral fat characteristics. This indicates 
Citation: Yamanaka Y, Shinno H, Kurose S, Tsutsumi H, Kimura Y (2013) Trial Evaluation of Visceral Fat Characteristics by Abdominal Bioelectrical Impedance Method. J Diabetes Metab 4: 292. doi:10.4172/2155-6156.1000292

Page 4 of 4

that the evaluation of visceral fat characteristics from V/A is important in addition to the evaluation of visceral fat area, because we believe that high density in visceral adipose tissue increases insulin resistance in obese female outpatients. To confirm what is the most significant correlation of V/A except HOMA-R, we performed stepwise multiple regression analysis. As a result, we confirmed that the final significant independent variable was peakVO $/ \mathrm{W}$. This indicates that low motor ability such as low peakVO $/ \mathrm{W}$ affects $\mathrm{V} / \mathrm{A}$ and is associated with high density in visceral adipose tissue. The lower the functional capacity of the obese female outpatients, the less exercise they perform, and the lower the density of visceral adipose tissue, the more physiological activation they have.

We report that the visceral fat characteristics (density) from V/A are not directly associated with VFA by CT (area). Hence the evaluation of visceral fat characteristics by V/A is important for diabetes care and so on. We suggest that not only the application of dietary restrictions but also the development of functional capacity through exercise therapy is important in the treatment of obesity.

\section{Acknowledgements}

We are grateful to Panasonic Co., Ltd for providing a trial device that is based on Ryo's eVFA method and to the staff of Health Science Center for their valuable assistance in measuring eVFA at Health Science Center, Kansai Medical University Hirakata Hospital.

\section{References}

1. Després JP, Lemieux I (2006) Abdominal obesity and metabolic syndrome. Nature 444: 881-887.

2. Rothney MP, Catapano AL, Xia J, Wacker WK, Tidone C, et al. (2012)
Abdominal visceral fat measurement using dual-energy X-ray: Association with cardiometabolic risk factors. Obesity (Silver Spring).

3. Matsuzawa $Y$ (2007) The metabolic syndrome and adipocytokines. Expert Rev Clin Immunol 3: 39-46.

4. Carr MC, Brunzell JD (2004) Abdominal obesity and dyslipidemia in the metabolic syndrome: importance of type 2 diabetes and familial combined hyperlipidemia in coronary artery disease risk. J Clin Endocrinol Metab 89: 2601-2607.

5. Ryo M, Nakamura T, Kihara S, Kumada M, Shibazaki S, et al. (2004) Adiponectin as a biomarker of the metabolic syndrome. Circ J 68: 975-981.

6. Lee JW, Lee HR, Shim JY, Im JA, Lee DC (2008) Abdominal visceral fat reduction is associated with favorable changes of serum retinol binding protein-4 in nondiabetic subjects. Endocr J 55: 811-818.

7. Matsuzawa Y, Funahashi T, Kihara S, Shimomura I (2004) Adiponectin and metabolic syndrome. Arterioscler Thromb Vasc Biol 24: 29-33.

8. Iribarren C, Darbinian JA, Lo JC, Fireman BH, Go AS (2006) Value of the sagittal abdominal diameter in coronary heart disease risk assessment: cohort study in a large, multiethnic population. Am J Epidemiol 164: 1150-1159.

9. Wabel P, Chamney P, MoissI U, Jirka T (2009) Importance of whole-body bioimpedance spectroscopy for the management of fluid balance. Blood Purif 27: $75-80$.

10. Coffman FD, Cohen S (2013) Impedance measurements in the biomedica sciences. Stud Health Technol Inform 185: 185-205.

11. Ryo M, Maeda K, Onda T, Katashima M, Okumiya A, et al. (2005) A new simple method for the measurement of visceral fat accumulation by bioelectrical impedance. Diabetes Care 28: 451-453.

12. Okauchi Y, Kishida K, Funahashi T, Noguchi M, Ogawa T, et al. (2010) Absolute value of bioelectrical impedance analysis-measured visceral fat area with obesity-related cardiovascular risk factors in Japanese workers. J Atheroscler Thromb 17: 1237-1245. 